\title{
Magnetite nanoplates decorated on anodized aluminum oxide nanofibers as a novel adsorbent for efficient removal of As(III)
}

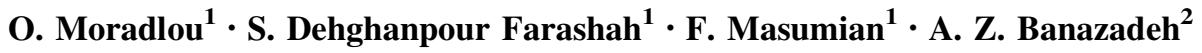

Received: 28 February 2015/Revised: 11 November 2015/ Accepted: 11 January 2016/Published online: 4 February 2016

(C) Islamic Azad University (IAU) 2016

\begin{abstract}
In this study, arsenic as an environmental topranked hazardous substance was efficiently removed by a novel adsorbent fabricated by magnetite $\mathrm{Fe}_{3} \mathrm{O}_{4}$ nanoplates decorated on anodized aluminum oxide (AAO) nanofibers. AAO nanofibers were prepared by anodic polarization method, and then $\mathrm{Fe}_{3} \mathrm{O}_{4}$ nanoplates were grown on AAObased substrate by hydrothermal method to fabricate $\mathrm{AAO} /$ $\mathrm{Fe}_{3} \mathrm{O}_{4}$ nanosorbent. Morphology of the fabricated adsorbents was characterized by field emission scanning electron microscopy (FE-SEM), and their crystallinity was studied by X-ray diffraction (XRD). Arsenic (III) removal potential of the proposed adsorbent from contaminated water samples was investigated by the determination of As(III) amounts in the samples by inductively coupled plasma optical emission spectroscopy before and after adsorption process at sub- $\mu \mathrm{g} \mathrm{L}^{-1}$ levels. The results showed that without pre- and post-treatments such as $\mathrm{pH}$ adjustment, As(III) was removed effectively from contaminated water samples by using the proposed adsorbent. $\mathrm{AAO} / \mathrm{Fe}_{3} \mathrm{O}_{4}$ sorbent showed excellent ability to remove $0.1 \mathrm{mg} \mathrm{L}^{-1}$ As(III) from water samples up to $96 \%$ uptake. Freundlich adsorption isotherm model was used to interpret the As(III) adsorption on proposed sorbent. The Freundlich isotherm
\end{abstract}

Electronic supplementary material The online version of this article (doi:10.1007/s13762-016-0941-3) contains supplementary material, which is available to authorized users.

O. Moradlou

moradlou@alzahra.ac.ir

1 Department of Chemistry, Alzahra University, Tehran, P.O. Box: 1993893973, Iran

2 Department of Chemical and Petrochemical Engineering, Standard Research Institute, Karaj, P.O. Box: 31745-139, Iran parameters $n$ and $k_{F}$ were obtained to be 2.2 and 10.2, respectively, representing the high affinity of proposed adsorbent for arsenic removal.

Keywords Magnetite $\mathrm{Fe}_{3} \mathrm{O}_{4}$ nanoplates $\cdot$ Anodized aluminum oxide nanofibers - Arsenic removal $\cdot$ Water samples
Abbreviations
AAO Anodized aluminum oxide
ANS Alumina-based nanosorbent
ICP-OES Inductively coupled plasma optical emission spectroscopy

\section{Introduction}

Arsenic is an important element that has impacts on public health, commercial interests, the environment, water and geopolitics. Arsenic (As) is a common environmental contaminant found naturally in groundwater. It is reported that As-contaminated groundwater has been identified as a serious threat in parts of world such as Bangladesh, Argentina, China, Taiwan, USA (Smedley and Kinniburgh 2002; Henke 2009), and it seems that more than 100 million people of the world may be at risk from arsenic-contaminated water (Henke 2009). The presence of As in groundwater is largely the result of minerals dissolving from rocks and soils. As a new arsenic rule in drinking water, U.S. Environmental Protection Agency (EPA) lowered the maximum concentration level of allowed As content in water systems from 50 to $10 \mathrm{ng} \mathrm{mL}^{-1}$ at 2002 (US EPA 2002). Arsenic and its compounds are among the naturally occurring contaminants worldwide, whose use is 
widespread as pigments (copper acetoarsenite, known as Paris green), medicinal agents (arsenic trioxide), insecticides (copper arsenite), herbicides (disodium methanearsonate) and as well-known semiconductor materials (gallium arsenide). The inorganic As compounds are very toxic and should be removed from water and food. Compared to inorganic arsenic, the organic forms of As are considered relatively non-toxic including precipitation and association with sulfides, sorption on clay minerals and carbonate associations (Henke 2009). In general, the toxicity of arsenic follows the order: inorganic As (III) species $>$ organic As (III) species $>$ inorganic As (V) species $>$ organic As (V) species $>$ elemental arsenic.

For the removal of As from water resources, different techniques have been developed including membrane filtration, coagulation/electro-coagulation (Ali et al. 2013), extraction (Mukhopadhyay et al. 2015) and adsorption processes (Daus et al. 2004). Among these methods, adsorption techniques using nanosorbents have their unique advantages including high ability for the treatment of Asrich water contents due to having high active sites in surface, simplicity in performance and operation, low recurring cost and production of less sludge volume (Basu and Ghosh 2011). Coagulation with ferric salts followed by filtration is the conventional and well-known technique. But, the biggest problem is the safe separation of the precipitate and the disposal of the contaminated coagulant sludge. Another advantage of the adsorption technique is that the spent arsenic adsorbents are a non-toxic solid waste and would not be characterized as hazardous waste and can be advantageously utilized as a component for manufacturing bricks (Hassan et al. 2014), thus encapsulating arsenic.

Among various adsorbents, iron oxide and aluminum oxide composites have extensively been studied and proposed as efficient adsorbents for As removal. Iron oxides are effective owing to high affinity between iron oxides and arsenic species. Consequently, up to now, various nanocomposites of zero-valent iron or iron oxides/hydroxides have been developed. Carbon materials linked with ferric oxides such as activated carbon fiber and graphene oxide have been investigated for As removal from water samples. Versatile magnetic graphene oxide composites (M/GO) were proposed for the efficient removal of arsenate (Sheng et al. 2012) and cobalt (II) (Liu et al. 2011) from water samples. Also, the magnetic composite of $\beta$ cyclodextrin grafted onto multiwall carbon nanotubes/iron oxides was developed for the removal of inorganic and organic pollutants ( $\mathrm{Hu}$ et al. 2010). Easy magnetic separation of these adsorbents from aqueous solutions is an important issue in these reports. Among ferric oxides, As removal abilities of aluminum oxide nanocomposites have widely been investigated. Polymer composite adsorbents based on aluminum oxide nanoparticles (Onnby et al. 2012) and self-assembled mesoporous $\gamma-\mathrm{Al}_{2} \mathrm{O}_{3}$ spherical nanoparticles (Patra et al. 2012) are the examples of this category.

Another strategy to increase the removal efficiency and adsorption capacity is using the binary mixtures of metal oxide nanostructures. The agglomerated $\mathrm{Fe}(\mathrm{III})-\mathrm{Al}(\mathrm{III})$ mixed oxide nanoparticles (Basu and Ghosh 2011) and binary mixtures of metal hydroxides and nanocrystallined Mg/Al-layered double hydroxides (Wu et al. 2013; Wen et al. 2013) were proposed for removal of arsenic from contaminated water. The main reason of these studies is to increase the removal efficiency as well as decrease the time necessary for efficient As removal.

This study aims to develop a new type of adsorbent based on anodized aluminum oxide on which magnetite $\mathrm{Fe}_{3} \mathrm{O}_{4}$ nanoplates were decorated as an effective adsorbent for removing As(III) from contaminated water samples. Anodization as a simple and inexpensive electrochemical method was used to fabricate alumina nanofibers with high surface area on the surface of $\mathrm{Al}$ sheet. To the best of our knowledge, there is not any report on As removal by the proposed AAO-based adsorbent. Arsenic contact time with adsorbent, initial As concentration, the effect of $\mathrm{pH}$ of solution, and the effect of the presence of some coexisting anions such as phosphate ion on As(III) removal were studied. Freundlich adsorption isotherm model was used to interpret the adsorption data, and the isotherm parameters were calculated.

\section{Materials and methods}

\section{Chemicals and apparatus}

All chemicals and solvents were of analytical grade. Oxalic acid, perchloric acid $\left(\mathrm{HClO}_{4}\right)$, urea $\left(\mathrm{CO}\left(\mathrm{NH}_{2}\right)_{2}\right)$, arsenic trioxide $\left(\mathrm{As}_{2} \mathrm{O}_{3}\right)$, iron (III) nitrate $\left(\mathrm{Fe}\left(\mathrm{NO}_{3}\right)_{3} \cdot 9 \mathrm{H}_{2} \mathrm{O}\right)$ and sodium hydroxide $(\mathrm{NaOH})$ were all from Merck. Ethanol was from Bidestan Co., Iran. All solutions used in the experiments were prepared by dissolving certain amounts of the compound in deionized water. As(III) stock solution of $100.0 \mu \mathrm{g} \mathrm{mL}^{-1}$ was prepared by dissolving an appropriate amount of $\mathrm{As}_{2} \mathrm{O}_{3}$ in $100-\mathrm{mL}$ volumetric flask in a small volume of $\mathrm{NaOH}(0.1 \mathrm{M})$ solution and diluting with DI water to the mark. The $\mathrm{pH}$ of this solution was adjusted to $\mathrm{pH} 7.0$ by adding droplets of $0.1 \mathrm{M} \mathrm{HCl}$ solution. All diluted As(III) solutions including subsequent working standard solutions and As(III) solutions in adsorption 
experiments were prepared from the stock solution by exact dilution.

For arsenic measurements, inductively coupled plasma optical emission spectrometer (ICP-OES, Thermo Scientific, Model IRIS Intrepid II) was used. The emission of arsenic was measured at $189.0 \mathrm{~nm}$. Argon gas flow (with the purity of $99.9999 \%$ ) for the sample introduction was $20 \mathrm{~L} \mathrm{~min}^{-1}$, and the supporting gas flow was $1 \mathrm{~L} \mathrm{~min}^{-1}$.

The surface topography of AAO films was studied using Thermo Microscope Autoprobe CP-Research atomic force microscopy (AFM), and the surface morphology of the samples was characterized by using field emission scanning electron microscopy (FE-SEM, ZEISS-Sigma VP, Germany). Infrared spectra of the samples were obtained by FT-IR spectrometer (Bruker, Germany). X-ray diffraction (XRD) analysis with $\mathrm{CoK}_{\alpha}$ radiation source was performed to determine the crystallinity of the samples.

\section{Synthesis of alumina nanofibers by anodization method}

Anodized aluminum oxide (AAO) nanofibers were fabricated via one-step anodization of aluminum (Al) sheet ( $99.9 \%$ purity, $0.4 \mathrm{~mm}$ thickness, $10 \times 30 \mathrm{~mm}$ ). Before anodization process, $\mathrm{Al}$ sheet was degreased with acetone and ethanol for two times for $5 \mathrm{~min}$ by sonication. Then, it was electro-polished in a 1:4 mixture of $\mathrm{HClO}_{4}$ and ethanol by applying $20 \mathrm{~V}$ anodic potential for $1 \mathrm{~min}$. The sample was washed with ethanol and deionized water and dried in air. Because of the electro-polishing process, an apparent mirror-like and shiny $\mathrm{Al}$ sheet was obtained. Anodization process was performed in an unstirred oxalic acid solution $(0.3 \mathrm{M})$ at a constant anodic potential of $45 \pm 1 \mathrm{~V}$ for $60 \mathrm{~min}$ in a two-electrode electrochemical system including $\mathrm{Al}$ sheet as anode and stainless steel sheet as cathode.

\section{Hydrothermal deposition of magnetite $\mathrm{Fe}_{3} \mathrm{O}_{4}$ nanoplates on alumina nanofibers}

Hydrothermal method was used for the deposition and growth of $\mathrm{Fe}_{3} \mathrm{O}_{4}$ nanoplates on AAO nanofibers to obtain various alumina-based nanosorbent (ANS) samples. $\mathrm{Fe}\left(\mathrm{NO}_{3}\right)_{3} \cdot 9 \mathrm{H}_{2} \mathrm{O}$ and $\left(\mathrm{NH}_{2}\right)_{2} \mathrm{CO}$ were used as precursors. At first, $4.0 \mathrm{~mL}$ of $\mathrm{Fe}(\mathrm{III})$ solution and $4.0 \mathrm{~mL}$ of urea with various concentrations (Table 1) were mixed in a beaker. Then, AAO substrate was vertically placed into a Teflonlined stainless steel autoclave and the mixture was transferred into autoclave and hydrothermally treated at $120^{\circ} \mathrm{C}$ for different times (Table 1). Then, the sample come out from the autoclave was washed with distilled water and dried in air.

\section{As(III) removal by fabricated alumina-based nanosorbents}

In a $250-\mathrm{mL}$ beaker, $100.0 \mathrm{~mL}$ of each of working As(III) solution with desired concentration was taken and the adsorbent (ANS-1 to ANS-7) was immersed into the solution vertically. Then, the working solution was magnetically stirred with the speed of $500 \mathrm{rpm}$. After the desired adsorption times, $2.0 \mathrm{~mL}$ of the solution was taken out of the vessel and analyzed for residual As concentration by ICP-OES at the emission wavelength of $189.0 \mathrm{~nm}$ under optimized experimental conditions.

\section{Results and discussion}

\section{Characterization of anodized aluminum oxide nanofibers}

AAO nanofibers were fabricated via one-step anodization of $\mathrm{Al}$ sheet in an unstirred oxalic acid solution $(0.3 \mathrm{M})$ under the applied constant anodic potential of $45 \mathrm{~V}$ for $60 \mathrm{~min}$. Usually, the growth of oxide film on the metallic substrate by applying constant anodic potential can be monitored by recording the current-time behavior. During the anodization process, the current density $(j)$ was changed with time as depicted in Fig. S1 (Supplementary data). This trend has been reported in the fabrication of alumina and titania nanotube array ( $\mathrm{Li}$ et al. 1998; Roy et al. 2011) films. The exponential decrease in $j$ as a function of time
Table 1 List of experimental conditions for the growth of magnetite $\mathrm{Fe}_{3} \mathrm{O}_{4}$ nanoplates on AAO nanofibers in different adsorbent samples

\begin{tabular}{llll}
\hline Adsorbent & $\mathrm{Fe}^{3+}$ concentration $(\mathrm{M})$ & Urea concentration $(\mathrm{M})$ & $\begin{array}{l}\text { Hydrothermal } \\
\text { reaction time (h) }\end{array}$ \\
\hline ANS-1 & $9.0 \times 10^{-4}$ & $9.0 \times 10^{-4}$ & 12 \\
ANS-2 & $2.5 \times 10^{-4}$ & $1.25 \times 10^{-2}$ & 12 \\
ANS-3 & $1.0 \times 10^{-2}$ & $5.0 \times 10^{-2}$ & 4 \\
ANS-4 & $1.0 \times 10^{-2}$ & $5.0 \times 10^{-2}$ & 8 \\
ANS-5 & $1.0 \times 10^{-2}$ & $5.0 \times 10^{-2}$ & 12 \\
ANS-6 & $1.0 \times 10^{-2}$ & $5.0 \times 10^{-2}$ & 24 \\
ANS-7 & $4.0 \times 10^{-2}$ & $2.0 \times 10^{-1}$ & 12 \\
\hline
\end{tabular}



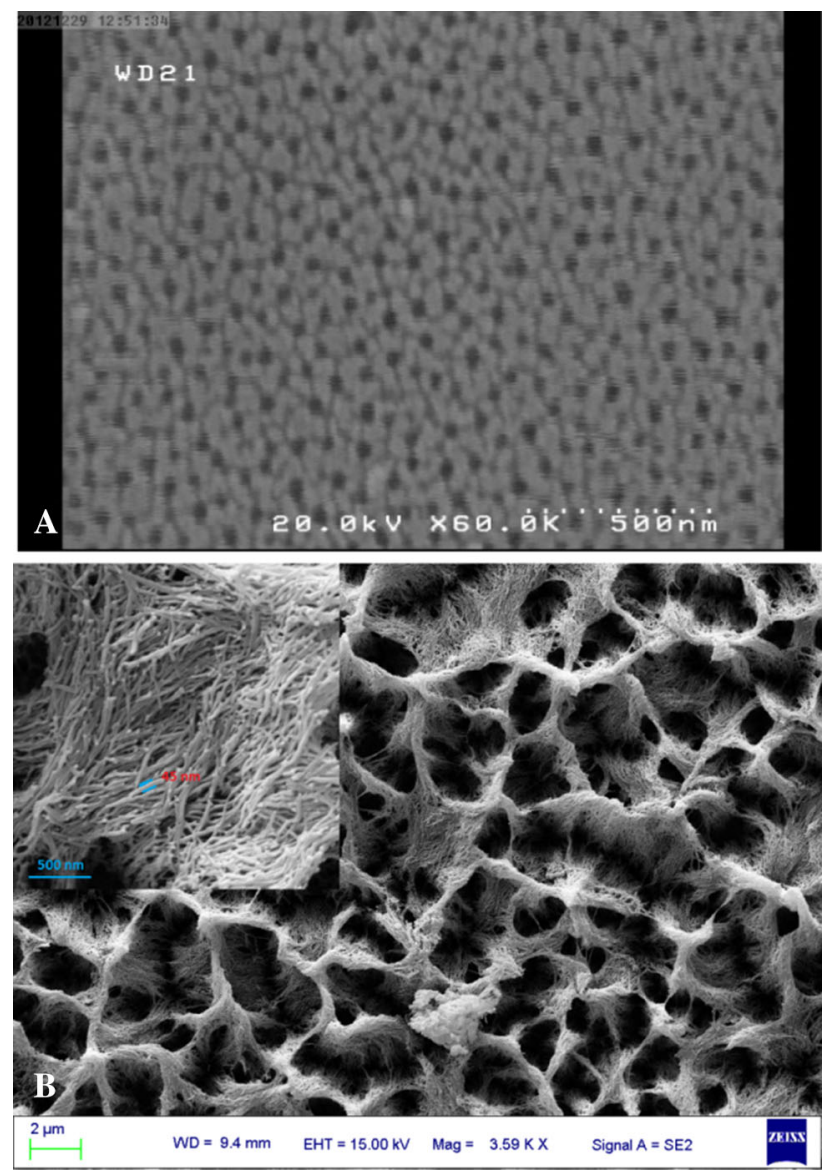

Fig. 1 SEM images of a alumina nanotube arrays fabricated under applied anodic potential of $45 \mathrm{~V}$ in a stirred oxalic acid solution $(0.3 \mathrm{M})$ at $10{ }^{\circ} \mathrm{C}$ for $20 \mathrm{~min}$, and $\mathbf{b}$ alumina nanofibers fabricated under applied anodic potential of $45 \mathrm{~V}$ in an unstirred oxalic acid solution $(0.3 \mathrm{M})$ at room temperature for $60 \mathrm{~min}$

after an initial sharp surge indicates the hard anodization conditions, while under the mild conditions, $j$ is maintained at a steady state value throughout the anodic process. Figure 1a shows the SEM image of alumina nanotubes grown by the anodization method in a stirred oxalic acid $(0.3 \mathrm{M})$ solution at $10{ }^{\circ} \mathrm{C}$ for $20 \mathrm{~min}$. Under these conditions, AAO nanotube arrays were obtained, as reported by the others (Zhao et al. 2005). However, under unstirred conditions and at room temperature $\left(T=25 \pm 2{ }^{\circ} \mathrm{C}\right)$ for $60 \mathrm{~min}$, the oxidation/solvation rate of pore mouth of nanotube walls began to increase and the formation rate (growth rate) of oxide layer decreased, and as Fig. 1b shows, AAO nanofibers with high surface area were formed. The inset in Fig. 1b shows the formation of dense clusters of nanofibers synthesized under the proposed experimental conditions. The nanofibers are on the order of $40-50 \mathrm{~nm}$ in diameter and several microns long. AFM analysis of fabricated AAO nanofibers (Fig. S2) indicated that the surface roughness of AAO film is increased about ten times in comparison with ordered AAO nanotube arrays. This indicates the effects of stirring, temperature and time of anodization process on the surface roughness of AAO film, as reported earlier based on the AFM studies of AAO (Skoneczny et al. 2004). AAO nanofibers with increased surface roughness are quite appropriate for adsorption applications of AAO-based nanosorbents. So, in further studies, AAO nanofibers were fabricated under the experimental conditions including applied anodic potential of $+45 \mathrm{~V}$, unstirred solution of $0.3 \mathrm{M}$ oxalic acid for $60 \mathrm{~min}$ at room temperature.

\section{Fabrication and characterization of magnetite $\mathrm{Fe}_{3} \mathrm{O}_{4}$ nanoplates grown on alumina nanofibers}

For the growth of $\mathrm{Fe}_{3} \mathrm{O}_{4}$ on AAO nanofibers, hydrothermal method was used under various conditions including different concentrations of $\mathrm{Fe}^{3+}$ and urea, and different hydrothermal reaction times at $120^{\circ} \mathrm{C}$ (Table 1). Figure 2a$\mathrm{d}$ shows the FE-SEM images of the samples. According to the SEM images, the morphology of $\mathrm{Fe}_{3} \mathrm{O}_{4}$ nanoplates is not affected considerably by the precursor concentrations. However, with an increase in the hydrothermal reaction time from $12 \mathrm{~h}$ in ANS-5 to $24 \mathrm{~h}$ in ANS-6, the morphology of the $\mathrm{Fe}_{3} \mathrm{O}_{4}$ nanoplates changes to string-like structures (Fig. 2c), indicating the significant effect of hydrothermal reaction time on the morphology of magnetite nanostructures. It is believed that the main advantage of the hydrothermal technique over other chemical methods is the abilities to control the morphology of nanostructures ranging from nanoparticles to nanorods, nanoplates or nanoflowers by properly choosing the temperature or time of the reaction without any major structure-directing agents or templates. So, it seems that the increase in hydrothermal reaction time increases the growth rate of $\mathrm{Fe}_{3} \mathrm{O}_{4}$ formation on $\mathrm{AAO}$ substrate and causes probable aggregation of nanoplates. However, an increase in hydrothermal reaction temperature (from 120 to $180^{\circ} \mathrm{C}$ ) did not affect the morphology of the samples (Fig. S3). From the FE-SEM images, the thickness of the $\mathrm{Fe}_{3} \mathrm{O}_{4}$ nanoplates is in the range of $20-30 \mathrm{~nm}$ with 200-300 nm in length. The elemental analysis of the sample layers by energy-dispersive X-ray spectroscopy (EDS) technique confirmed $\mathrm{Al}, \mathrm{Fe}$ and oxygen elements (Fig. S4).

Figure 3 shows the XRD pattern of $\mathrm{Fe}_{3} \mathrm{O}_{4}$-coated AAO nanofibers (sample ANS-5). The diffraction peaks of aluminum substrate have been shown in XRD pattern. Because of the amorphous structure of AAO fabricated by anodization process (Poinern et al. 2011), there is not any 

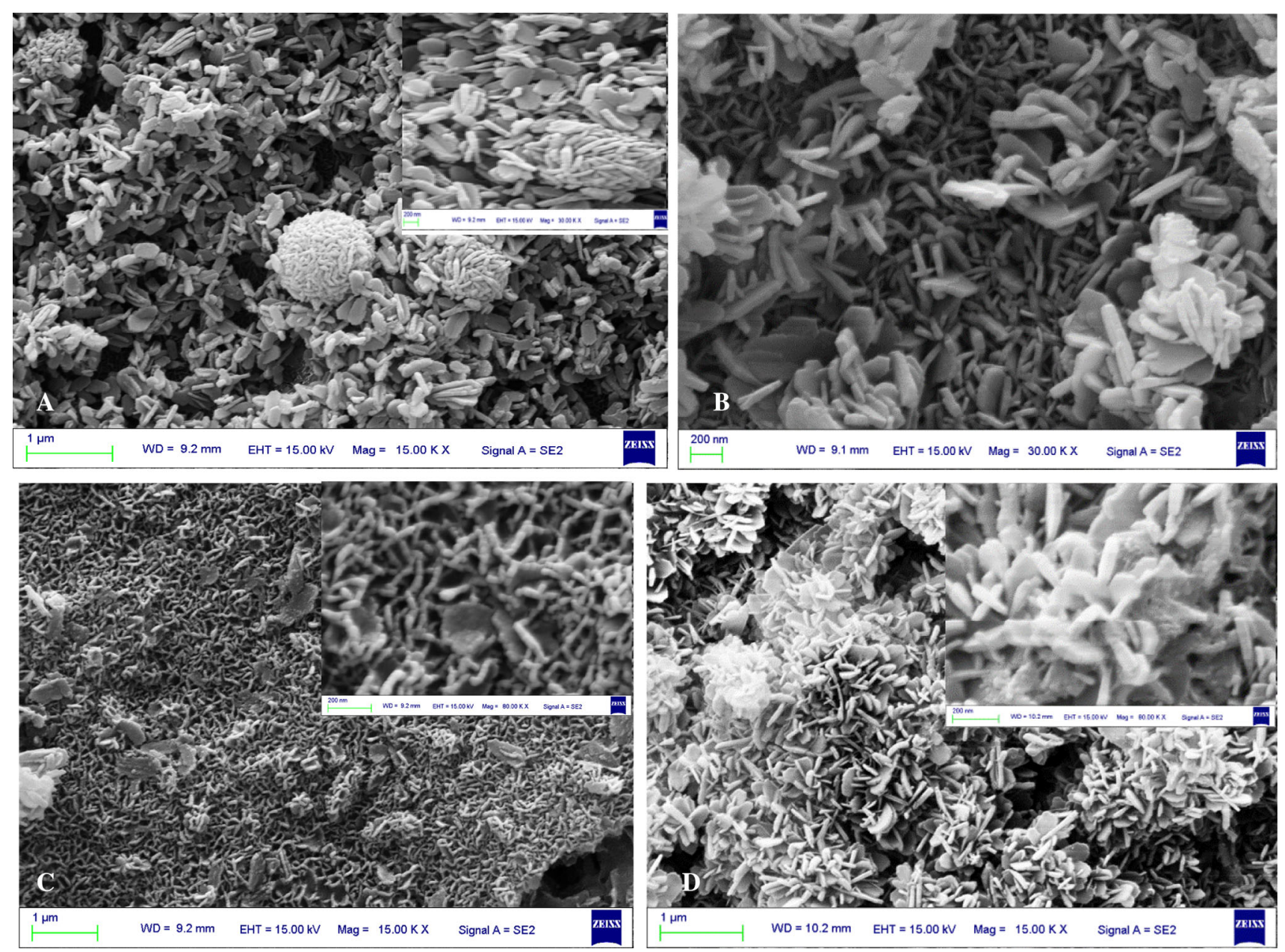

Fig. 2 FE-SEM micrographs of $\mathrm{Fe}_{3} \mathrm{O}_{4}$-decorated AAO samples. a ANS-2, b ANS-5, c ANS-6, d ANS-7. The hydrothermal reaction conditions for the fabrication of samples are depicted in Table 1

Fig. 3 XRD pattern of magnetite $\mathrm{Fe}_{3} \mathrm{O}_{4} / \mathrm{AAO}$ sample

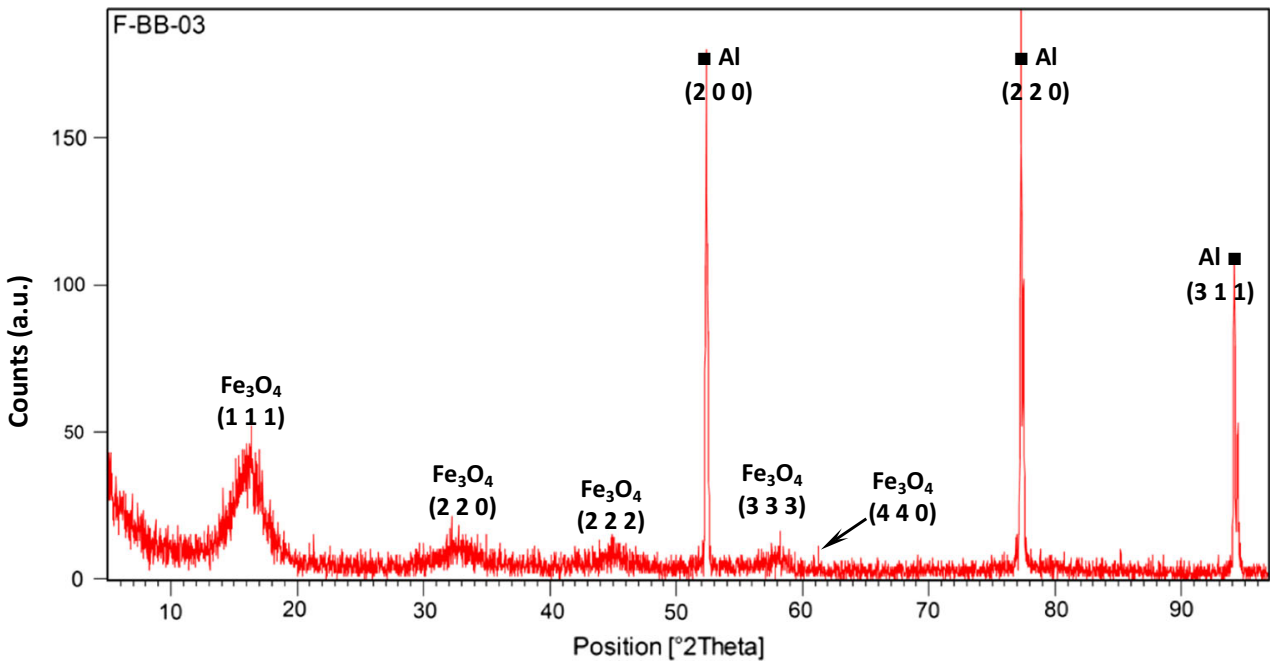

Springer 
corresponding peak in XRD pattern. The diffraction peaks of $\mathrm{Fe}_{3} \mathrm{O}_{4}$ reveal the nanocrystalline nature of the sample and match with the crystal phase of magnetite $\mathrm{Fe}_{3} \mathrm{O}_{4}$ (JCPDS No. 894319, 19-0629). The intensive peaks corresponding to the substrate suppress the diffraction peaks of $\mathrm{Fe}_{3} \mathrm{O}_{4}$ on the substrate. In addition, these diffraction peaks are broadened owing to small crystallite size of $\mathrm{Fe}_{3} \mathrm{O}_{4}$. According to Scherrer's equation, the mean grain size of crystallites was obtained to be $27.3 \mathrm{~nm}$.

Infrared spectra of $\mathrm{Fe}_{3} \mathrm{O}_{4}$-coated $\mathrm{AAO}$ sample are shown in Fig. S5. The characteristic absorption bands of the $\mathrm{Fe}-\mathrm{O}$ bond for bulk $\mathrm{Fe}_{3} \mathrm{O}_{4}$ are around 375 and $570 \mathrm{~cm}^{-1}$, due to the $\mathrm{Fe}-\mathrm{O}$ stretching mode of the tetrahedral and octahedral sites. In $\mathrm{Fe}_{3} \mathrm{O}_{4}$ nanoplates, however, these peaks were shifted to 480 and $633 \mathrm{~cm}^{-1}$, respectively (Fig. S5). The blue shift of these absorption bands can be attributed to the effect of the finite size of nanoplates (Ma et al. 2003). The bands at 1649 and $3300 \mathrm{~cm}^{-1}$ are attributed to the $\mathrm{H}-\mathrm{O}-\mathrm{H}$ bending and $\mathrm{O}-\mathrm{H}$ stretching modes of the adsorbed water molecules on the surface of the sample.

\section{Arsenic adsorption on $\mathrm{Fe}_{3} \mathrm{O}_{4}$ nanoplate-coated alumina nanofibers}

All of the fabricated alumina-based nanosorbent (ANS) samples (Table 1) and AAO nanofiber (without decorated $\mathrm{Fe}_{3} \mathrm{O}_{4}$ nanoplates) were examined for their arsenic removal potentials. The effects of various experimental parameters including the adsorbate concentration, $\mathrm{pH}$ of the solution,

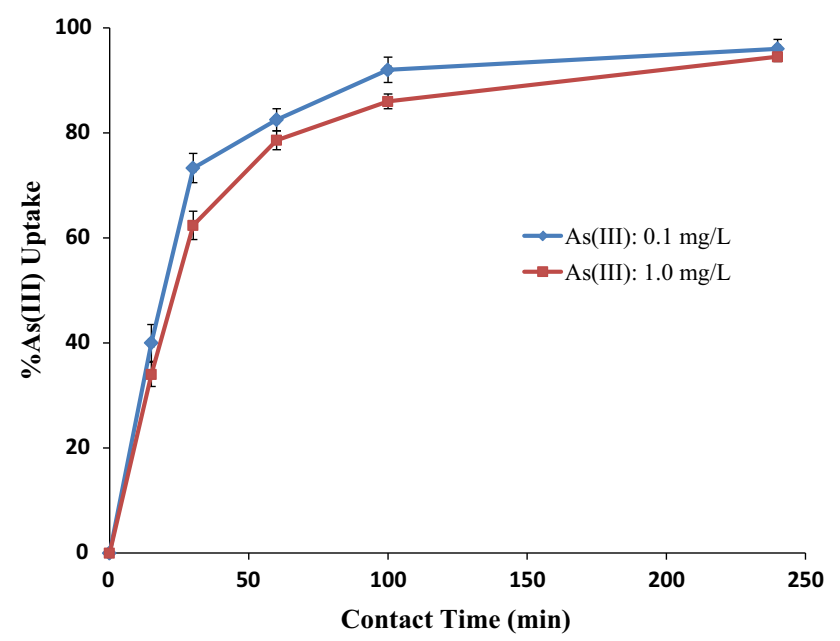

Fig. 4 Effect of contact time on As(III) removal by ANS-5 adsorbent at neutral $\mathrm{pH}$ and at the initial As(III) concentrations of $0.1 \mathrm{mg} \mathrm{L}^{-1}$ (filled diamond) and $1.0 \mathrm{mg} \mathrm{L}^{-1}$ (filled square) time of the adsorption process and the presence of other anionic competitors such as phosphate and carbonate ion on the performance of nanosorbent were investigated.

\section{The effect of contact time}

The reaction time required to achieve adsorption equilibrium of As(III) uptake onto ANS-based nanosorbents is important to evaluate the removal efficiency of the adsorbent materials. Figure 4 and Table 2 show the effect of time of the adsorption process on As(III) removal by ANS5 nanosorbent at neutral $\mathrm{pH}$ at initial concentrations of 0.1 and $1.0 \mathrm{mg} \mathrm{L}^{-1}$ of As(III). The results show a significant removal of As(III) with the increase in contact time. In the beginning, the uptake rate of $\mathrm{As}(\mathrm{III})$ is faster compared to the subsequent slower uptake rate, due to the availability of more active surface sites of $\mathrm{Fe}_{3} \mathrm{O}_{4}$ to the adsorbate in solution. At equilibrium, the removal efficiencies of As(III) at the initial concentrations of 0.1 and $1.0 \mathrm{mg} \mathrm{L}^{-1}$ were 96.0 and $94.5 \%$, respectively. The adsorption equilibrium was achieved in almost $240 \mathrm{~min}$. As Fig. 4 shows, the adsorption reached equilibrium quickly and the adsorption rate was considerably fast in the first contact time of about $100 \mathrm{~min}$, and few changes were observed from 100 to 240 min indicating that the adsorption of As(III) on ANS-5 nanosorbent was mainly attributed to the chemical sorption or electrostatic interaction between As(III) and sorbent. Moreover, to gain a better understanding of adsorption mechanism, the effect of $\mathrm{pH}$ of solution on adsorption process was studied, and to quantify the sorption data, the Freundlich model was used to simulate the experimental data.

The same experiments were carried out using other nanosorbent samples. The results are shown in Fig. S6 and Table 3. As the results show, among the adsorbents studied, ANS-5 sample has highest As(III) removal efficiency

Table $2 \%$ As (III) removal efficiency of ANS-5 adsorbent with the initial $\mathrm{As}(\mathrm{III})$ concentrations of 0.1 and $1.0 \mathrm{mg} \mathrm{L}^{-1}$

\begin{tabular}{lll}
\hline $\begin{array}{l}\text { Contact } \\
\text { time }(\mathrm{min})\end{array}$ & $\begin{array}{l}\text { \% As(III) removal } \\
(\text { average } \pm \mathrm{SD}, n=3)\end{array}$ & $\begin{array}{l}\text { \% As(III) removal } \\
(\text { average } \pm \mathrm{SD}, n=3)\end{array}$ \\
\hline 0 & 0 & 0 \\
15 & $40.0 \pm 3.5$ & $34.0 \pm 2.3$ \\
30 & $73.3 \pm 2.8$ & $62.4 \pm 2.7$ \\
60 & $82.5 \pm 2.1$ & $78.6 \pm 1.8$ \\
100 & $92.0 \pm 2.4$ & $86.0 \pm 1.4$ \\
240 & $96.0 \pm 1.8$ & $94.5 \pm 0.9$
\end{tabular}

a The initial concentration of As(III) was $0.1 \mathrm{mg} \mathrm{L}^{-1}$

b The initial concentration of As(III) was $1.0 \mathrm{mg} \mathrm{L}^{-1}$ 
Table 3 Effect of competing anions on As(III) removal at $\mathrm{pH} 7.0$ at the equilibrium time of $240 \mathrm{~min}$

\begin{tabular}{|c|c|c|c|c|c|c|}
\hline \multirow[t]{2}{*}{ Adsorbent } & \multicolumn{3}{|c|}{$\%$ As(III) removal ${ }^{\mathrm{a}}$} & \multicolumn{3}{|c|}{$\% \mathrm{As}(\mathrm{III}) \mathrm{removal}^{\mathrm{b}}$} \\
\hline & - & $\begin{array}{l}\text { Phosphate } \\
\text { ion }(0.01 \mathrm{M})\end{array}$ & $\begin{array}{l}\text { Carbonate } \\
\text { ion }(0.02 \mathrm{M})\end{array}$ & - & $\begin{array}{l}\text { Phosphate } \\
\text { ion }(0.01 \mathrm{M})\end{array}$ & $\begin{array}{l}\text { Carbonate } \\
\text { ion }(0.02 \mathrm{M})\end{array}$ \\
\hline ANS-1 & 56.0 & 27.5 & 53.2 & 42.5 & 25.2 & 39.0 \\
\hline ANS-2 & 72.0 & 38.0 & 69.0 & 65.0 & 26.1 & 61.4 \\
\hline ANS-3 & 89.8 & 46.0 & 83.5 & 83.2 & 47.5 & 74.5 \\
\hline ANS-4 & 94.1 & 52.0 & 87.1 & 91.8 & 37.0 & 86.2 \\
\hline ANS-5 & 96.0 & 51.6 & 91.0 & 94.5 & 43.4 & 91.6 \\
\hline ANS-6 & 92.5 & 53.4 & 85.0 & 92.0 & 41.0 & 86.0 \\
\hline ANS-7 & 91.0 & 54.2 & 83.8 & 93.0 & 39.3 & 84.0 \\
\hline
\end{tabular}

a The initial concentration of As(III) was $0.1 \mathrm{mg} \mathrm{L}^{-1}$

b The initial concentration of As(III) was $1.0 \mathrm{mg} \mathrm{L}^{-1}$

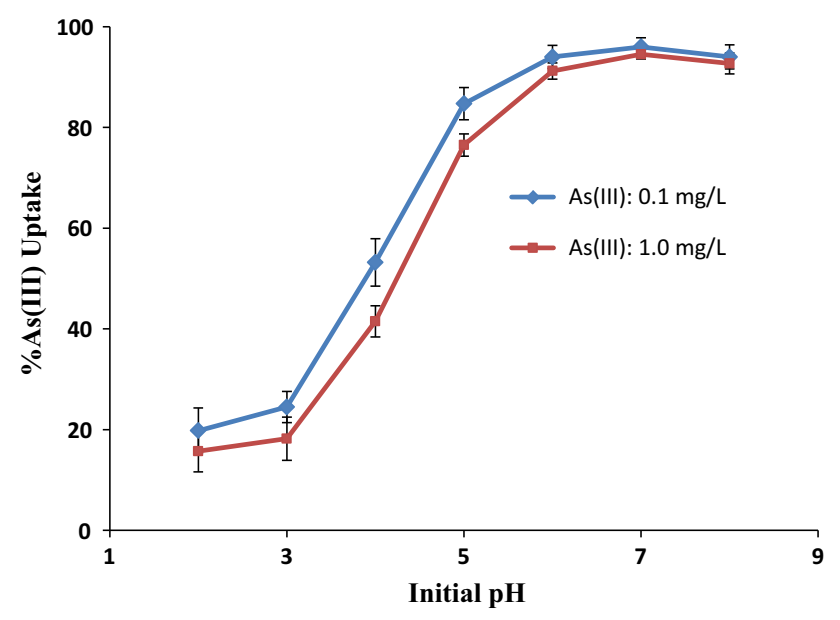

Fig. 5 Effect of $\mathrm{pH}$ on As(III) removal using ANS-5 adsorbent at the initial As(III) concentrations of $0.1 \mathrm{mg} \mathrm{L}^{-1}$ (filled diamond) and $1.0 \mathrm{mg} \mathrm{L}^{-1}$ (filled square). The $\mathrm{pH}$ values are the initial values

in neutral media. In addition, all samples have lower As removal potential by higher initial As(III) concentration (1.0 $\left.\mathrm{mg} \mathrm{L}^{-1}\right)$ in comparison with lower one $\left(0.1 \mathrm{mg} \mathrm{L}^{-1}\right)$, due to the saturation of available active surface sites of $\mathrm{Fe}_{3} \mathrm{O}_{4}$ to the adsorbate in solution containing higher As amounts. Also, ANS samples with lower $\mathrm{Fe}_{3} \mathrm{O}_{4}$ loading on AAO such as ANS-1 have lower As removal efficiency especially by higher initial As(III) amounts. The unmodified AAO nanofiber film after the contact time of $12 \mathrm{~h}$ shows the arsenic uptake of $26 \%$ in As solution with $0.1 \mathrm{mg} \mathrm{L}^{-1}$. It is probably due to the hydration of $\mathrm{Al}_{2} \mathrm{O}_{3}$ at the surface of AAO film at longer contact times. Due to the electron deficiency at the surface, $\mathrm{Al}_{2} \mathrm{O}_{3}$ has strong affinity for the target anions and thus it was extensively used as adsorbent for the removal of arsenic species (Patra et al. 2012).

\section{The effect of $\mathrm{pH}$}

Arsenic removal experiments were done under the various $\mathrm{pH}$ values of As(III) solution (Fig. 5). As the results show, the highest As(III) removal efficiencies were obtained at neutral $\mathrm{pH}$ values from 6.0 to 8.0. In acidic media, the removal efficiencies are low. The $\mathrm{pH}$-dependent behavior of arsenic adsorption on ANS samples shows that the adsorption process seems to be controlled by several factors including specific adsorption and/or Coulombic interactions. To understand the As(III) adsorption mechanism, $\mathrm{pH}$ of zero point charge $\left(\mathrm{pH}_{\mathrm{ZPC}}\right)$ of ANS-5 was determined describing the condition that the electrical charge density on surface is zero. The $\mathrm{pH}_{\mathrm{ZPC}}$ of ANS-5 was determined to be about 5.2, below which the surface of sorbent is positively charged and above this amount, the surface of sorbent is negatively charged. On the other hand, the speciation diagram of arsenite shows that below $\mathrm{pH}$ of $\sim 8$, the main species is non-charged $\mathrm{H}_{3} \mathrm{AsO}_{3}$ (Smedley and Kinniburgh 2002) and above that the anionic species of As(III) are dominant. Considering these facts, the adsorption of As(III) on ANS-5 sorbent is mainly governed by chemical sorption. The same behaviors in $\mathrm{pH}$ dependence of arsenic removal by iron oxide composites have been reported earlier (Basu and Ghosh 2011; Tang et al. 2011). During the adsorption process, a few changes were observed in $\mathrm{pH}$ of solutions (Table S1, Supplementary data). A little increase in the solution $\mathrm{pH}$ values under the acidic conditions, and a little decrease in $\mathrm{pH}$ under the alkaline conditions is probably due to the protonation/deprotonation reactions of sorbent surface, respectively. In addition, in acidic media, the solubility of iron oxide nanosheet causes the loss of material, as confirmed by the determination of iron content of acidic adsorbate solution after removal process. 


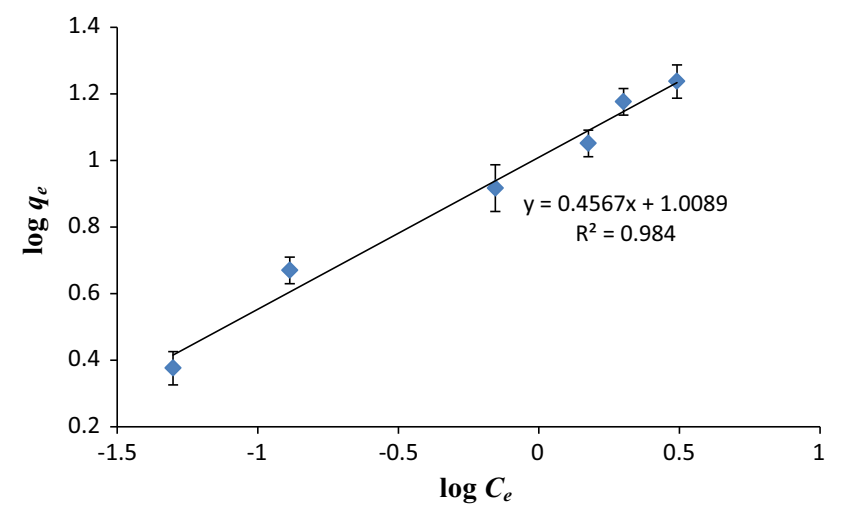

Fig. 6 Freundlich adsorption isotherm for As(III) adsorption on ANS-5 adsorbent

\section{The effect of competing anions}

The effect of some coexisting anions such as chloride, nitrate, phosphate and carbonate ions on arsenic adsorption by different ANS samples was examined. In the presence of phosphate ions, the removal efficiency of the samples greatly degrades, but the effect of carbonate anion is not significant (Table 3). The significant interference of phosphate ions on As(III) sorption is mainly due to its electrostatic attraction to the adsorbent surface at neutral media. The most abundant anions present in natural water such as chloride and nitrate ions even at high concentrations did not show deterioration effect on the adsorption of As(III) on the adsorbent sample.

The feasibility of the fabricated ANS-5 sample to remove As(III) from real water samples was tested by using tap water containing various cations and anions including $\mathrm{Ca}^{2+}, \mathrm{Mg}^{2+}, \mathrm{Na}^{+}, \mathrm{Cl}^{-}, \mathrm{HCO}_{3}{ }^{-}$and $\mathrm{CO}_{3}{ }^{2-}$ in their natural levels. In a $250-\mathrm{ml}$ beaker, $100.0 \mathrm{~mL}$ of the tap water sample spiked with $0.1 \mathrm{mg} \mathrm{L}^{-1} \mathrm{As}$ (III) solution was taken and ANS-51 sorbent was immersed into the solution vertically. Then, the working solution was magnetically stirred with the speed of $500 \mathrm{rpm}$ for $240 \mathrm{~min}$. The results showed that $95 \pm 2 \%(n=3)$ of the spiked As(III) was removed from the water samples without any pre- and post-treatments such as $\mathrm{pH}$ adjustment.

\section{Adsorption isotherm}

Freundlich isotherm is widely used for describing the adsorption from aqueous solutions and has become a kind of standard equation for characterizing adsorption processes in water treatment. Freundlich adsorption isotherm equation (Eq. 1) was used to interpret the nature of arsenic adsorption on sorbent. So, the adsorption behavior was fitted with a Freundlich isotherm.

$q_{e}=k_{F} C_{e}^{1 / n}$

where $q_{e}$ is the mass of contaminant adsorbed per unit weight of the adsorbent $\left(\mathrm{mg} \mathrm{g}^{-1}\right)$ at equilibrium, $C_{e}$ is the concentration of adsorbate $\left(\mathrm{mg} \mathrm{L}^{-1}\right)$ in solution at equilibrium, and $k_{F}$ and $n$ are the experimental parameters which depend on the system of adsorbent and adsorbate. $k_{F}$ characterizes the strength of adsorption, and $n$ is related to the energetic heterogeneity of the adsorbent surface and determines the curvature of the isotherm. Figure 6 demonstrates the As(III) equilibrium adsorption isotherm obtained at near-neutral $\mathrm{pH}$ environment. As it is clear, the plot of $\log q_{e}$ versus $\log C_{e}$ for various initial As(III) concentrations is found to be linear, indicating the applicability of the classical adsorption isotherm to this adsorbate-adsorbent system. From the intercept and the slope of plot, the parameters $n$ and $k_{F}$ were obtained to be 2.2 and 10.2 , respectively. The higher value for $k_{F}$ indicates the high affinity for arsenic and high adsorbent loading that can be achieved, and $n$ values between 1 and 10 indicate the favorable adsorption.
Table 4 Comparison of various adsorbents for As(III) removal from water samples

\begin{tabular}{lccl}
\hline Adsorbent & $k_{F}\left(\mathrm{mg} \mathrm{g}^{-1}\right)$ & $n$ & References \\
\hline Magnetite & 10.0 & 2.5 & Mayo et al. (2007) \\
Aluminum-doped manganese copper ferrite polymer & 0.85 & 1.5 & Malana et al. (2011) \\
Activated alumina & 0.22 & 2.2 & Singh and Pant (2004) \\
Activated alumina grains & 1.21 & 1.53 & Lin and Wu (2001) \\
$\mathrm{TiO}_{2}$ (Degussa P25) suspension & 14.0 & 1.4 & Dutta et al. (2004) \\
$\mathrm{TiO}_{2}$ (Hombikat UV100) suspension & 13.0 & 1.8 & Dutta et al. (2004) \\
$\mathrm{Agglomerated} \mathrm{Fe}(\mathrm{III})-\mathrm{Al}(\mathrm{III})$ mixed oxide nanoparticles & 2.53 & 1.85 & Basu and Ghosh (2011) \\
Nanoscale zero-valent iron & 3.50 & 3.27 & Kanel et al. (2005) \\
Ultrafine $\alpha-\mathrm{Fe}_{2} \mathrm{O}_{3}$ nanoparticles & 12.55 & 2.53 & Tang et al. (2011) \\
Magnetite-reduced graphene oxide composite & 3.79 & 2.32 & Chandra et al. (2010) \\
Magnetite $\mathrm{Fe}_{3} \mathrm{O}_{4} / \mathrm{AAO}$ & 10.2 & 2.2 & This work \\
\hline
\end{tabular}


Table 4 presents Freundlich constants, i.e., $k_{F}$ and $n$ for As(III) adsorption by the proposed magnetite $\mathrm{Fe}_{3} \mathrm{O}_{4} / \mathrm{AAO}$ thin film and other adsorbents reported previously. The data show that As(III) adsorption in all the studies cited as well as our study is favorable. From the data obtained for As removal by using $\mathrm{Fe}_{3} \mathrm{O}_{4} / \mathrm{AAO}$ nanosorbent, it is clear that the proposed sorbent is very useful adsorbent for arsenic uptake from contaminated water samples.

\section{Conclusion}

A simple two-step method was proposed for the fabrication of AAO-based nanosorbent for arsenic removal from contaminated water samples in neural media. All of the experimental conditions were optimized for getting satisfactory results. The results showed that without pre- and post-treatments of the water samples, such as $\mathrm{pH}$ adjustment, $\mathrm{As}(\mathrm{III})$ can be effectively removed by $\mathrm{Fe}_{3} \mathrm{O}_{4} / \mathrm{AAO}$ nanosorbent. This does not require the separation of adsorbent material from the adsorbate solution by filtration. This is the main advantage of proposed nanosorbent. The Freundlich isotherm was fitted to the experimental data to interpret the nature of adsorption mechanism. $n$ and $k_{F}$ are obtained to be 2.2 and 10.2 , representing the high affinity of proposed nanosorbent for As(III) removal.

Acknowledgments The authors would like to thank the Research Council of Alzahra University for financial support.

\section{References}

Ali I, Asim M, Khan TA (2013) Arsenite removal from water by electro-coagulation on zinc-zinc and copper-copper electrodes. Int J Environ Sci Technol 10:377-384

Basu T, Ghosh UC (2011) Arsenic(III) removal performances in the absence/presence of groundwater occurring ions of agglomerated $\mathrm{Fe}(\mathrm{III})-\mathrm{Al}(\mathrm{III})$ mixed oxide nanoparticles. J Ind Eng Chem 17:834-844

Chandra V, Park J, Chun Y, Lee JW, Hwang IC, Kim KS (2010) Water-dispersible magnetite-reduced graphene oxide composites for arsenic removal. ACS Nano 4:3979-3986

Daus B, Wennrich R, Weiss H (2004) Sorption materials for arsenic removal from water: a comparative study. Water Res 38:2948-2954

Dutta PK, Ray AK, Sharma VK, Millero FJ (2004) Adsorption of arsenate and arsenite on titanium dioxide suspensions. J Colloid Interf Sci 278:270-275

Hassan KM, Fukushi K, Turikuzzaman K, Moniruzzaman SM (2014) Effects of using arsenic-iron sludge wastes in brick making. Waste Manag 34:1072-1078

Henke K (2009) Arsenic: environmental chemistry, health threats and waste treatment, 1st edn. Wiley, Chichester
Hu J, Shao D, Chen C, Sheng G, Li J, Wang X, Nagatsu M (2010) Plasma-induced grafting of cyclodextrin onto multiwall carbon nanotube/iron oxides for adsorbent application. J Phys Chem B 114:6779-6785

Kanel SR, Manning B, Charlet L, Choi H (2005) Removal of arsenic(III) from groundwater by nanoscale zero-valent iron. Environ Sci Technol 39:1291-1298

Li F, Zhang L, Metzger RM (1998) On the growth of highly ordered pores in anodized aluminum oxide. Chem Mater 10:2470-2480

Lin TF, Wu JK (2001) Adsorption of arsenite and arsenate within activated alumina grains: equilibrium and kinetics. Water Res 35:2049-2057

Liu M, Chen C, Hu J, Wu X, Wang X (2011) Synthesis of magnetite/graphene oxide composite and application for cobalt(II) removal. J Phys Chem C 115:25234-25240

Ma M, Zhang Y, Yu W, Shen H, Zhang H, Gu N (2003) Preparation and characterization of magnetite nanoparticles coated by amino silane. Colloid Surf A Physicochem Eng Asp 212:219-226

Malana MA, Qureshi RB, Ashiq MN (2011) Adsorption studies of arsenic on nano aluminium doped manganese copper ferrite polymer (MA, VA, AA) composite: kinetics and mechanism. Chem Eng J 172:721-727

Mayo JT, Yavuz C, Yean S, Cong L, Shipley H, Yu W, Falkner J, Kan A, Tomson M, Colvin VL (2007) The effect of nanocrystalline magnetite size on arsenic removal. Sci Technol Adv Mater 8:71-75

Mukhopadhyay S, Hashim MA, Allen M, Gupta BS (2015) Arsenic removal from soil with high iron content using a natural surfactant and phosphate. Int J Environ Sci Technol 12:617-632

Onnby L, Pakade V, Mattiasson B, Kirsebom H (2012) Polymer composite adsorbents using particles of molecularly imprinted polymers or aluminium oxide nanoparticles for treatment of arsenic contaminated waters. Water Res 46:4111-4120

Patra AK, Dutta A, Bhaumik A (2012) Self-assembled mesoporous $\gamma$ $\mathrm{Al}_{2} \mathrm{O}_{3}$ spherical nanoparticles and their efficiency for the removal of arsenic from water. J Hazard Mater 201-202:170-177

Poinern GEJ, Ali N, Fawcett D (2011) Progress in nano-engineered anodic aluminum oxide membrane development. Materials 4:487-526

Roy P, Berger S, Schmuki P (2011) $\mathrm{TiO}_{2}$ nanotubes: synthesis and applications. Angew Chem Int Ed 50:2904-2939

Sheng G, Li Y, Yang X, Ren X, Yang S, Hub J, Wang X (2012) Efficient removal of arsenate by versatile magnetic graphene oxide composites. RSC Adv 2:12400-12407

Singh TS, Pant KK (2004) Equilibrium, kinetics and thermodynamic studies for adsorption of As(III) on activated alumina. Separ Purif Technol 36:139-147

Skoneczny W, Jurusik J, Burian A (2004) Investigations the surface morphology of $\mathrm{Al}_{2} \mathrm{O}_{3}$ layers by atomic force microscopy. Mater Sci Poland 22:265

Smedley PL, Kinniburgh DG (2002) A review of the source, behaviour and distribution of arsenic in natural waters. Appl Geochem 17:517-568

Tang W, Li Q, Gao S, Shang JK (2011) Arsenic (III, V) removal from aqueous solution by ultrafine $\alpha$-Fe2O3 nanoparticles synthesized from solvent thermal method. J Hazard Mater 192:131-138

Us EPA (2002) Minor clarification of national primary drinking water regulation for arsenic. Fed Reg 67:78203-78209

Wen T, Wu X, Tan X, Wang X, Xu A (2013) One-pot synthesis of water-swellable $\mathrm{Mg}-\mathrm{Al}$ layered double hydroxides and graphene oxide nanocomposites for efficient removal of $\mathrm{As}(\mathrm{V})$ from aqueous solutions. ACS Appl Mater Interfaces 5:3304-3311 
Wu X, Tan X, Yang S, Wen T, Guo H, Wang X, Xu A (2013) Coexistence of adsorption and coagulation processes of both arsenate and NOM from contaminated groundwater by nanocrystallined Mg/Al layered double hydroxides. Water Res 47:4159-4168
Zhao Y, Chen M, Zhang Y, Xu T, Liu W (2005) A facile approach to formation of through-hole porous anodic aluminum oxide film. Mater Lett 59:40-43 